I understand, Dr. Chree's basis for his most anxious doubts; and the object of my letter was to try to remove at least this form of doubt from the minds of astronomers and responsible magneticians.

One more quite minor point I may take the opportunity of mentioning, though it is connected rather with a letter of Dr. Chree's in the Times than with his letter in Nature.

(7) Disturbance of terrestrial rainfall-say an increase for a short period due to influx of cosmic nuclei-need not be supposed to modify the usual local distribution of rain, but only to increase its amount in the customary localities.

This I only venture to say very tentatively, and with no dogmatism at all. It is clear that the total rainfall all over the earth during a long period cannot exceed what the sun can evaporate in approximately the same period, and therefore depends more on the sun's total activity than on anything else. It is also clear that rain is a local circumstance, and that the conditions which determine whereabouts rain shall fall are mainly local. But I question whether either of these propositions really negatives the idea that cosmic causes may occasionally affect the rainfall during any given month, even in a specified locality.

Oliver LodGe.

\section{Why has the Moon no Atmosphere?}

Proctor ("The Moon," p. 334) says :-“" It has been held, and not without some degree of evidence in favour of the theory, that in our Moon we have a picture of our Earth, as she will be at some far distant date... when her oceans and atmosphere have disappeared through the action of the same circumstances (whatever they may be) which have caused the Moon to be airless and oceanless.'

The following considerations suggest what the circumstances referred to may have been, and present what seems a possible cause for the absence of an atmosphere.

(I) Apart from all theory, we know that the sun exerts a repulsive force on matter around him. The phenomena of comets' tails show this as clearly as the streamers from a flagstaff show that a wind is blowing. Kepler first suggested the existence of this force. Sir John Herchel, in his essay on comets, said, more than forty years ago, that " they have furnished us with a proof, amounting to demonstration, of the existence of a repulsive force directed ... from the Sun."

(2) Maxwell in 1873 deduced from his electromagnetic theory the pressure of light, which Arrhenius in 1900 applied to explain the formation of comets' tails. Each particle projected from the comet, under the influence of the sun's heat when nearing the sun, being submitted to two opposing forces, viz. gravitation and the pressure of light, he pointed out that since the pressure varied as the surface, while the weight varied as the volume, i.e. one compared with the other, varied as the square of number compared with its cube, then, when the particles were small enough, the repulsive force of the pressure might be many times as great as the force of attraction, and drive away the particles with great velocity.

As a common example of such action, I may remark that we have the case of a wind blowing on a newly macadamised road or on a single stone on the road. While the stones are unbroken the wind cannot move them, but when they are crumbled to powder it sweeps them away in clouds.

(3) In this way the sun exercises a sort of sifting process in space, sweeping away very small particles and drawing the larger ones towards him.

(4) Assuming that the moon had an atmosphere for many ages, the particles would be acted on by the repulsive force of the sun radiating from its centre, and by gravity directed to the centre of gravity of the moon. During the time that the moon retained its atmosphere it is evident that gravity must have been the preponderating force. The atoms, as Dalton called them, were not small enough to allow the pressure of light to prevail over the weight.

(5) But the atmosphere has disappeared, and we have to account for this fact. Can the particles have been in any wav reduced in size?

If we are sure that the chemical atoms, as Dalton called NO. 2086, VOL. 8I] them, despite the protests of such men as Davy, Wollaston and Berzelius, cannot be decomposed or disintegrated, then an hypothesis to the contrary must be rejected.

(6) But the recent discoveries in radio-activity are opposed to this. It has been shown that the radio-active elements are disintegrating slowly and gradually from their own internal energy. The process has been going on for indefinite time, although only lately discovered accidentally because of certain radiations. Have we reason to believe that it is limited to these elements? Prof. Rutherford has pointed out that the existence of rayless changes in these elements " indicates the possibility that undetected changes of a similar character may be taking place in the non-radio-active elements" ("Radio-activity," p. 455, 2nd edition). If we suppose that such changes took place at the outer surface of the moon's atmosphere, resulting in particles sufficiently small, then part after part of the atmosphere may have been stripped away until the present condition has been reached.

(7) The same process may be going on now with the earth's atmosphere, notwithstanding the greater force of gravity.

Briefly, if the atmosphere of the moon was ever driven away -the repulsive force of the sun (pressure of light) is the only driving force we know of-the component particles must have been originally too heavy to be driven off, and were therefore in some way reducible; the transformations in the radio-active elements suggest a possible process.

Thus the present condition of the moon is an argument for the disintegration of some of the non-radio-active elements, and the argument is the stronger in proportion to the difficulty of finding a solution otherwise to this old astronomical problem.

Montreal, Canada, September 30 .

\section{A "Canaan Stone."}

Captain B-, of the Brixham (Devon) trawler fleet, recently showed me what he termed a "Canaan stone." He told me that in the hands of his wife's mother it had effected many miraculous cures of diseases of the eye, and that by its use she had been especially successful in curing cataract. The stone was a polished sphere of agate, translucent, and of a faintly greenish-yellow tint, containing several red-brown patches due to the presence of iron. It was about $\frac{3}{4}$-inch in diameter, and had been drilled through the centre, as though it had at one time formed part of a necklace. The treatment simply consisted in "striking" (i.e. gently rubbing) the eye with the stone. No prayers or incantations were used, but it was essential that different parts of the stone should be used in different diseases, and the part used also varied with the colour of the patient's eyes. The stone was rubbed actually on the conjunctiva, not on the lids. The secret of the exact method of treatment died with the old lady, who is reported to have had quite an extensive ophthalmic practice, and I was appealed to in order that I might explain the secret to the present owners of the stone. Beyond the fact that the stone had been bought by its late owner from a man in Cornwall for $4 \mathrm{ol}$., no history was available.

The following extract from the Book of Tobit suggested itself to me as a possible explanation of the origin of the belief in the curative value of the stone :-

"When Tobias and Raphael came to the river Tigris, a fish leaped out of the water and would have devoured him, but the young man laid hold of it and drew it to land. The Angel bade Tobias open the fish, and take the heart, and the liver, and the gall, and put them up safely. . . And the Angel said ... As for the gall: it is good to anoint a man that a whiteness in his eyes shall be healed. ... Tobias met his father at the door, and strake of the gall on his father's eyes ... and Tobit recovered his sight."

It does not require a great stretch of the imagination to see a resemblance between this translucent, greenish. yellow stone, with its red-brown patches, and the distended gall-bladder of a fish, excised with small portions of liver adherent to its surface. The expression "to strike," for to anoint or rub, is still quite common in Devon. In the country districts a usual treatment for sprains or abrasions 